\title{
A IMPORTÂNCIA DA CRIATIVIDADE COMO FATOR DE INOVAÇÃO PARA AS CORPORAÇÕES E O DESIGN
}

\author{
Maristela Gomes de Camargo; Me.; Universidade Estadual de Maringá \\ marysthella_1@hotmail.com
}

\begin{abstract}
Resumo: A criatividade é um tema importante a ser pesquisado e discutido, pois tem uma relação profunda com a evolução da humanidade e com os avanços tecnológicos, sociais, econômicos, da saúde, entre outros. Sabe-se que esta é uma característica inerente ao homem, que todas as pessoas são potencialmente criativas, mas esse potencial difere de pessoa para pessoa, apenas em grau. Isso ocorre devido aos bloqueios e imposições limitadoras sofridas durante o processo de desenvolvimento do ser. Para tanto, é necessário desenvolvê-la em todo o seu potencial. Inovação e criatividade se relacionam intimamente e são fatores primordiais para o crescimento das organizações. $O$ design, como área de produção criativa de produtos, sistemas, necessita de profissionais capazes de antever problemas e vislumbrar soluções necessárias para os mesmos. Este artigo tem como objetivo compreender a criatividade como processo mental intrínseco ao homem e sua importância como agente produtor de inovação, bem como contribuir para a produção científica nesta área de conhecimento.
\end{abstract}

Palavras-chave: Criatividade; potencial criativo; inovação, design.

\begin{abstract}
Creativity is an important topic to be researched and discussed; it has a deep relationship with the evolution of humanity and the social, technological, economic advances, health, among others. It is known that is an inherent feature of man, which all persons are potentially creative, but this potential differs from person to person, only in degree. This is due to blockages and limiting impositions incurred during the development process of being. Therefore, it is necessary to develop it into its full potential. Innovation and creativity are closely related and are key factors for the growth of organizations. The design, as an area of creative production of products, systems, needs professionals able to foresee problems and visualize solutions required for the same. This article aims to understand creativity as a mental process intrinsic to man and its importance as a producer of innovation and contribute to the scientific literature in this area of knowledge.
\end{abstract}

Keywords: Creativity; creative potential; innovation, design. 


\section{INTRODUÇÃO}

A criatividade é um processo mental, essencial ao ser humano, que se apresenta materialmente quando o homem produz ideias, comportamentos e conceitos inovadores e diferentes. Apesar de ser um potencial da mente humana, a criatividade difere de pessoa para pessoa, pois o ambiente (pressão) influi grandemente no desenvolvimento e aprimoramento deste potencial. As imposições limitadoras levam o indivíduo a desacreditar de sua capacidade criativa, provocando resistência, medo e rejeição ao ato de criar.

O pensamento criativo está estritamente ligado à percepção, à memória, associação e ao ambiente. Considera-se que o ato criativo é constituído por pessoa, processo, produto e contexto (ambiente), ou seja, o pensamento criativo é produzido por meio de uma sequência de ordenações e compromissos internos e externos.

Por se tratar de um constructo complexo e multidimensional, encontram-se diversas definições e concepções de criatividade. Entretanto, muitas concepções afirmam o caráter inovador deste constructo, que se apresenta em produzir o novo, ou resolver problemas.

Criatividade e inovação se relacionam intimamente, e seu trabalho em conjunto aparece como um fator primordial para transformar ideias em novos produtos e serviços, desenvolver novas tecnologias e formas de produção, sistemas, serviços, entre outros. O design tem uma participação importante na produção de novos produtos, processos e transferência de novas tecnologias, os designers precisam desenvolver seu potencial criativo para criarem produtos que satisfaçam as necessidades dos consumidores levando em consideração a realidade da empresa, prevendo problemas e encontrando soluções.

A criatividade é um instrumento valioso para as empresas e organizações e não pode ser esquecido nem deixado em segundo plano no planejamento de produtos, processos ou serviços.

Considerando estes fatores, o presente estudo aborda conceitos sobre criatividade e seu caráter inovador. Busca-se analisar sua importância como fator de inovação para a produção de produtos, processos e serviços e como instrumento de diferenciação e crescimento das organizações. Para conhecer sobre seus conceitos, processos e outras características, procedeu-se a pesquisa bibliográfica para estruturar este estudo.

\section{CONCEITOS SOBRE CRIATIVIDADE}

A criatividade vem sendo estudada por psicólogos e estudiosos da área cognitiva, que investigam como e em que medida essa característica da mente humana se processa. Seus estudos são recentes, ocorreram de forma mais significativa a partir de 1950. Ainda há muito que desvendar nesse processo. Devido a sua complexidade, pode-se encontrar diversas definições de criatividade, algumas conflitantes outras com características comuns, deste modo, observa-se que não há uma definição exata e unânime sobre este fenômeno nem como ocorre exatamente o processo mental que o envolve. "Isso se deve ao fato de que a criatividade, assim como a inteligência, constitui-se em um constructo complexo, dinâmico e multidimensional." (ALENCAR, FLEICH, BRUNO-FARIA, 2010, p. 14)

Sabe-se que a criatividade é uma característica inerente ao homem, em que se combinam os efeitos das capacidades cognitivas aos efeitos relativos ao 
temperamento e ao caráter do indivíduo. Sendo assim, pode ser entendida como um processo que integra toda a personalidade nos aspectos que dizem respeito à eficiência produtiva do indivíduo. (SEABRA, 2008)

Para Oliveira, Silva e Cavalcante (2011) a definição de criatividade não é fácil, porém, diversos autores concordam com a afirmação de que este processo sofre influência de aspectos cognitivos, afetivos, sociais e inconscientes, combinados de forma particular por cada sujeito. Assim, tudo que é percebido e feito pelo homem reflete seu ordenar íntimo, pois o que ele comunica corresponde a um modo particular de ser que não existia e nem existirá outro idêntico já que é parte dele.

Considerando o ordenar íntimo do homem, encontra-se, ainda, a concepção de que a criatividade é "resultado de uma interação mutuamente benéfica entre a pessoa e o ambiente." E que este fenômeno seria melhor compreendido em quatro dimensões constitutivas, pessoa, ambiente, processo criativo e produto criativo, ou pessoa, processo, produto e contexto. (ALENCAR, FLEICH, BRUNO-FARIA, 2010, p. 12; PEARSON, 2011)

A interação pessoa/ambiente repousa no fato de que o homem se desenvolve como ser a partir de sua existência dentro de um contexto social, de um meio cultural, entretanto, sendo parte deste contexto também é um ser único, singular, com seu temperamento, hábitos e atitudes emocionais. Neste sentido, em cada ser humano molda-se seu comportamento por meio de padrões culturais e históricos, "do grupo em que ele, indivíduo, nasce e cresce." (OSTROWER, 2009, p. 11)

Pode-se dizer, então, que 0 ato criativo está ligado a uma sequência de ordenações e compromissos internos e externos, ou seja, que "o potencial criador elabora-se nos múltiplos níveis do ser sensível-cultural-consciente do homem, e se faz presente nos múltiplos caminhos em que o homem procura captar e configurar as realidades da vida." (OSTROWER, 2009, p. 27)

Dentre as concepções de criatividade encontra-se, ainda, a geração de novas ideias. Autores como Sternberg (2000) e Aznar (2005) apud Dias, Enumo e Azevedo Junior (2004, p. 430) conceituam que a “(...) criatividade envolve a produção de alguma coisa que é ao mesmo tempo original e de valor", ou "uma aptidão individual em produzir o novo, ou em produzir novas combinações, ou resolver problemas." Lubart (2000, p. 16) conceitua a criatividade como a "capacidade de realizar uma produção que seja ao mesmo tempo nova e adaptada ao contexto na qual ela se manifesta." Mas para que as ideias geradas tenham caráter criativo, precisam ter uma aplicação prática, pois "de nada valeria produzir uma ideia inovadora sem que esta possuísse uma utilidade prática." (DELL'ISOLA, 2009)

Para Ostrower (2009) criar é basicamente formar, é dar forma a algo novo e que em todo formar, todo construir é um destruir. Ao se configurar algo e ao defini-lo, novas alternativas, novas possibilidades surgem, pois um problema é formado por diversos subproblemas que devem ser resolvidos para se resolver o todo, sendo assim, o que se definiu inicialmente, vai se transformando, a ideia se constrói, e ao ser transformada se destrói e se reconstrói, sucessivamente. Cada decisão tomada representa um ponto de partida para o processo de transformação que está sempre recriando o impulso que o criou.

A criatividade é uma característica inerente ao homem, todo ser humano é naturalmente criativo, entretanto, nem todas as pessoas têm a mesma medida de criatividade, há diferença de pessoa para pessoa, mas apenas em grau. 
Entretanto as imposições limitadoras da sociedade provocam o desprezo pela imaginação, pela fantasia, o medo da experimentação, e o condicionamento do pensamento e do olhar. (ALENCAR, 1990)

Os pensamentos convencionais são reflexos do condicionamento do olhar, o olhar está condicionado a ver somente o que lhe é habitual, não vê novas possibilidades, novas formas ou utilidades para o objeto em foco. Habituar-se a ver além do que se enxerga é liberar a mente a criar novas conexões e produzir o que não é convencional.

Para se desenvolver o potencial criativo é necessário à pessoa ver o que ninguém mais vê, utilizando-se de métodos "de saber ver e fazer com que seu pensamento se torne visível, é pensar naquilo que ninguém mais está pensando." (Oliveira, 2010, p. 84)

Para reforçar o conceito de Oliveira (2010) pode-se resgatar Baxter (2000, p. 177) no tocante ao projeto conceitual, "a maior dificuldade no projeto conceitual é liberar a mente para se chegar a conceitos originais [...] isso exige a superação dos bloqueios à criatividade, que surgem em consequência dos pensamentos convencionais."

\subsection{O Processo Criativo}

O processo criativo depende de fatores externos e internos para poder acontecer. Ostrower (2009) o define como sendo um fenômeno criador que envolve a capacidade da mente humana em compreender, relacionar, ordenar, configurar e significar. A mente relaciona os acontecimentos e os configura com as experiências de vida armazenadas na memória e Ihes dá um significado, que é o resultado do trabalho concomitante entre seus níveis consciente e inconsciente.

Neste contexto, a autora aponta que o pensamento criativo se ordena dentro do ser consciente-sensível-cultural. A consciência e a sensibilidade fazem parte da herança biológica do homem, ou seja, são comportamentos inatos, já a cultura diz respeito ao desenvolvimento social, as formas de convívio do homem. (OSTROWER, 2009)

Oliveira (2010) reforça esta afirmação dizendo que o indivíduo carrega uma herança genética e suas próprias experiências, que a cultura é um sistema simbólico com um conjunto de regras para representação do pensar e do agir do indivíduo.

A cultura é produto de tudo que aqueles que pertencem a ela são capazes de criar, de desenvolver e deixar para os outros. A cultura é o próprio indivíduo, no seu tempo e espaço e, deste modo, define o que o indivíduo produz. (FREITASMAGALHÃES, 2003). A cultura molda o indivíduo e a sensibilidade é o meio através do qual as informações são aprendidas na formação do ser social.

A sensibilidade está relacionada à percepção, que é descrita como a produção mental das sensações, é ela quem delimita o que o homem é capaz de sentir e compreender; corresponde a uma ordenação seletiva dos estímulos captados pelos receptores sensoriais criando uma barreira entre o que é percebido e aquilo que não é. O indivíduo criador é mais sensível ao seu meio, é observador e mais aberto ao seu ambiente e as coisas que acontecem ao seu redor. (KNELLER, 1978)

"A realidade é apreendida, portanto, via olhar, histórico e socialmente construído, que caracteriza um modo de ver o mundo através de determinada lente, de um ângulo específico." (DOS REIS et. al, 2004, p 53) 
O pensamento criativo está estritamente ligado à percepção, à memória, associação e ao ambiente. Mentalmente não há como separar as etapas do pensamento criativo, entretanto, pode-se dizer que ele se processa em fases que se relacionam intimamente, que ocorrem concomitantemente e em ciclos.

O primeiro modelo do pensamento criativo foi elaborado pelo inglês Graham Wallas, em que este ocorria em quatro etapas: preparação, incubação, iluminação e verificação, (PEARSON, 2011). Esse mesmo modelo foi apresentado por Kneller (1978), entretanto este atribuiu uma etapa anterior à preparação que denominou primeira apreensão.

Löbach (2001, p. 141) define as fases do processo criativo em: "fase de preparação; fase de geração; fase de avaliação e fase de realização."

No modelo de Wallas o processamento inconsciente das informações aprendidas cruzam-se com as experiências próprias do indivíduo, nesse processo ocorrem o trabalho da memória e das associações. (KNELLER, 1978).

"A memória é o armazenamento relativamente permanente da informação aprendida, [...] o cérebro processa, armazena e recupera informações de diferentes maneiras para se adequar às diferentes necessidades" As informações aprendidas são interligadas a experiências já vividas, isso torna possível cruzar informações que o orientarão na realização de ações que the sejam solicitadas em momentos da vida. (WIDMAIER, RAFF, STRANG, 2006, p 249)

Em relação à memória Ostrower (2009) escreve que "A memória torna possível interligar o ontem ao amanhã, compreender o instante atual como extensão mais recente de um passado."

"As associações provêm de áreas inconscientes ou pré-conscientes e compõem a essência do mundo imaginário," (OSTROWER, 2009, p. 20). Um mundo de fantasia, não relacionado a devaneios ou ao fantástico, mas relacionado a um mundo experimental, em que há o pensar e agir em hipóteses, o associar objetos e eventos, manipulando-os mentalmente. Associações são correspondências, proposições produzidas a partir de semelhanças, ressonâncias pessoais construídas de forma particular em cada indivíduo amarradas a experiências anteriores e a todo um sentimento de vida.

A associação de ideias é entendida como o processo cerebral em que a mente, a partir de uma ideia inicial (indutora), é imediatamente levada a originar outra ideia. Isso ocorreria em razão de alguma "conexão natural" existente entre ambas. (ASSOCIAÇÃO, 200-)

A imaginação está ligada à aquisição de imagens, assim não é possível separar imagem de imaginação. Por isso a aquisição, o armazenamento e processamento de imagens são tão importantes. (DISCHINGER et. al, 2006)

Existem modos diferentes de construção de imagens, alguns são descritos a seguir.

A imagem sensorial é obtida por meio da observação direta do objeto, também é chamada de imagem perceptiva, pois está relacionada com os sentidos. A imagem mnemônica resulta da recordação reativada pela memória; A imagem fantástica é produto da imaginação, aparece sem objeto, tem pouca nitidez e é influenciada pela vontade; A imagem que forma o conteúdo dos sonhos é denominada onírica e é de origem mnemônica ou imaginativa; A imagem pareidólica, fruto da imaginação, e origina-se de imagens reais. (CENTRO DE MEDICINA, 2004?) 
"A importância de se cultivar a imaginação passou a ser ressaltada e o uso das imagens sensoriais, especialmente as imagens visuais, passou a ser apontada como um dos recursos para favorecer o desenvolvimento e clarificação de ideias." (ALENCAR, 1990, p. 78).

"O processo criativo está extremamente relacionado com as experiências de cada pessoa, com imagens que são armazenadas na memória. Estas imagens vão alimentar a capacidade de imaginação." (DISCHINGER, MARQUES, KINDLEIN, 2006)

As profissões relacionadas à criação, em especial o Design, trabalham com a imaginação como base para uma atividade criadora profusa de sentidos e produção. (DISCHINGER, MARQUES, KINDLEIN, 2006)

\subsection{Caráter Inovador da Criatividade}

A capacidade que o homem possui em produzir ideias, produtos, invenções, objetos artísticos novos e originais, e considerados valiosos para áreas como das Ciências, da Tecnologia e da Arte, resulta da ação criativa. (SEABRA, 2007)

A originalidade dos empreendimentos produzidos pelo homem é resultado da junção entre criatividade e inovação, visto que inovação pode ser entendida como introdução de novidade, ou ação que resulta em novos produtos, processos e serviços, conceitos que também caracterizam o ato criativo.

Deste modo, Bruno-Faria (2010, p.116) aponta que criatividade, inovação e mudança organizacional se relacionam intimamente, "de modo que a criatividade de indivíduos e grupos no contexto do trabalho pode gerar inovações que, por sua vez, provocam mudanças diferenciadas."

O papel da inovação é conceber produtos inovadores bem como métodos de produção igualmente inovadores, pois "muitas vezes uma solução inovadora em um modo de produção pode permitir que o custo dessa produção seja bastante reduzido, gerando mais lucros e se diferenciando dos concorrentes." (PEARSON, 2011, p.75)

Em relação aos produtos a inovação promove mudanças significativas nas potencialidades dos produtos, bem como o aperfeiçoamento dos produtos existentes no mercado.

Pode-se afirmar, então, que "Inovação é a implementação das ideias, processos, produtos ou serviços originários da criatividade de indivíduos ou grupos na organização." Entretanto, para que haja inovação não basta apenas produzir algo novo e de valor, o produto da inovação precisa ser passível de implementação. (BRUNOFARIA, 2010, p. 115)

No mundo atual, com o desenvolvimento tecnológico, científico, industrial, dentre outros, surgiram problemas de ordem ambiental, da saúde, de desorganização social e outros, que exigem criatividade na busca de soluções dos problemas decorrentes desse desenvolvimento. (OLIVEIRA, 2010)

A capacidade de inovar, "transformar ideias em novos produtos e serviços, desenvolver novas tecnologias e formas de produção, introduzir produtos e serviços em novos mercados," surge como um fator primordial aos países desenvolvidos e em desenvolvimento para atingirem a prosperidade futura. (SMITH-BINGAM, 2006 apud ALENCAR, FLEICH, BRUNO-FARIA, 2010, p.12)

Neste sentido, pode-se afirmar que em todas as organizações a criatividade, como fator de inovação, surge como uma importante ferramenta de sobrevivência das corporações dentro da contemporaneidade, "pois para se construir o futuro é 
imprescindível ser criativo no presente e ser capaz de ver aquilo que ninguém mais vê, ser um visionário e inovador." (OLIVEIRA, 2010, p. 87)

Como pode ser visto, a novidade é um fator importante no desenvolvimento de produtos, sendo assim, a criatividade não pode ser tratada como uma simples casualidade, pois é ela quem atribui a qualidade inovadora ao produto idealizado e produzido.

Carvalho e Back (2000) escrevem que "o desfio atual das empresas é melhorar os produtos e sua produção, e a metodologia de projeto tem demonstrado ser útil para a obtenção de produtos inovadores, existem diversos meios para se alcançar a inovação."

O design participa da inovação e transmissão de novas tecnologias, e o designer criativo pode instigar as empresas a expandirem seus limites em relação ao desenvolvimento de novos produtos.

"O crescimento e a evolução das organizações precisa sair da mesmice, mas isso só acontecerá quando abrirem espaço para o elemento chamado criatividade $\mathrm{e}$ inovação." (FELDMAN, RUTHES, CUNHA, 2008, p. 240)

Entretanto, Gurgel (2006) constata em seu estudo, que, infelizmente, grande parte das empresas enaltece ferramentas avançadas de gestão e relegam a criatividade. A criatividade só é valorizada quando há uma situação de urgência, quando as empresas se sentem pressionadas a modificar ou se adaptar a novas demandas.

\section{CONCLUSÃO}

A criatividade é um processo mental complexo e extremamente importante para o desenvolvimento da humanidade. Essa característica do homem promoveu avanços em diversos campos de conhecimento. Apesar de sua importância, são recentes os estudos e pesquisa nessa área da cognição. Dentre as diversas áreas em que se faz necessária a sua aplicação para se atingir o caráter de inovação encontra-se a de desenvolvimento de produtos. Nos projetos de design a criatividade é parte integrante do desenvolvimento dos produtos e se faz presente na resolução de problemas. $\mathrm{O}$ caráter criativo e inovador só pode ser considerado válido se o resultado da ideia idealizada tiver viabilidade e utilidade prática. Criatividade e inovação se relacionam intimamente e são fatores essenciais para o crescimento das organizações. Neste sentido, os designers, projetistas de produtos e processos devem buscar desenvolver e aprimorar seu potencial criativo e imaginário por meio de técnicas que favoreçam o desenvolvimento e clarificação de ideias. A criatividade suas potencialidades e aplicações são questões que devem ser divulgadas e apreciadas, pois ainda há muito a ser pesquisado e analisado sobre suas formas de manifestação.

\section{REFERÊNCIAS}

ALENCAR, Eunice M. L. Soriano de. Como desenvolver o potencial criador: um guia para a liberação da criatividade em sala de aula. 10a ed., Petrópolis: Vozes, 1990.

ALENCAR, Eunice M. L. Soriano de; FLEICH, Denis de Souza; BRUNO-FARIA, Maria de Fátima. A medida da criatividade: possibilidades e desafios. In: ALENCAR, Eunice M. L. Soriano de; BRUNO-FARIA, Maria de Fátima; FLEICH, Denis de Souza. Medidas de criatividade: teoria e prática. Porto Alegre: Artmed, 2010. p. 11-34. 
BRUNO-FARIA, Maria de Fátima. Indicadores de clima para a criatividade no ambiente de trabalho. . In: ALENCAR, Eunice M. L. Soriano de; BRUNO-FARIA, Maria de Fátima; FLEICH, Denis de Souza. Medidas de criatividade: teoria e prática. Porto Alegre: Artmed, 2010. p. 113-134.

ASSOCIAÇÃO DE IDEIAS. Disponível na internet por http em: < http://www.psiqweb.med.br/site/DefaultLimpo.aspx?area=ES/VerDicionario\&idZDicio nario=117>. Acesso em 18 mar. 2014

BAXTER, Mike. Projeto de produto: guia prático para o design de novos produtos. 3 ed. São Paulo: Blucher, 2011.

CARVALHO, Marco. A. de; BACK, Nelson. Rumo a um modelo para a solução criativa de problemas nas etapas iniciais do desenvolvimento de produtos. In: CONGRESSO BRASILEIRO DE GESTÃO DO DESENVOLVIMENTO DE PRODUTO, 2, 2000, São Carlos. Anais...São Carlos: UFSC, 2000.

CENTRO DE MEDICINA PSICOSSOMÁTICA E PSICOLOGIA MÉDICA. Alteração da Sensopercepção. Disponível na internet por http em:

<http://www.medicinapsicossomatica.com.br/glossários/percepção.> Acesso em 07 mar. 2014.

DELL'ISOLA, Roberto. Mentes brilhantes: como desenvolver todo o potencial do cérebro. 2 ed. São Paulo: Universo dos Livros, 2009.

DIAS, Tatiane L.; ENUMO, Sônia R. F.; AZEVEDO JUNIOR, Romildo R. Influências de um programa de criatividade no desempenho Cognitivo e acadêmico de alunos com dificuldade de aprendizagem. Psicologia em Estudo. Maringá, v. 9, n. 3, p. 429-437, set./dez. 2004.

DISCHINGER, M. C. Torri; MARQUES, André Canal; KINDLEIN, Wilson Jr. O imaginário e sua importância para as atividades projetuais. In: CONGRESSO DE PESQUISA \& DESENVOLVIMENTO EM DESIGN, 7, 2006. Curitiba. Anais...70 P\&D Design, Curitiba: UFPR, 2006.

DOS REIS, Alice Casanova; ZANELLA, Andréa Vieira; FRANÇA, Kelly Bedin; DA ROS, Sílvia Zanatta. Reflexões sobre o Olhar Estético em Contexto de Escolarização Formal. Psicologia: Reflexão e Crítica. Porto Alegre, v.17 n.1, p. 51-60, 2004.

FELDMAN, Liliane Bauer; RUTHES, Rosa Maria; CUNHA, Isabel Cristina Kowal Olm. Criatividade e inovação: competências na gestão de enfermagem. Revista Brasileira de Enfermagem. Brasília. v. 61, n 2, p. 239-42, março-abril, 2008. Disponível na internet por http em <http://www.scielo.br/scielo.php?script=sci_arttext\&pid=S003471672008000200015.> Acesso em 01 mai. 2014.

FREITAS-MAGALHÃES, Armindo. Psicologia da Criatividade: estudo sobre o desenvolvimento da expressão criadora da criança. 7 ed. Porto: ISCE-Edições 
Universidade Fernando Pessoa, 2003. Disponível na internet por http em: <pt.scribd.com/doc/6919333/Livro-ISCEPsicologia-da-criatividade> Acesso em 29 fev. 2012.

FUENTES, Rodolfo. A prática do design gráfico: uma metodologia criativa. 2 ed.rev. São Paulo: Edições Rosari, 2009.

GURGEL, Marcos Freire. Criatividade \& inovação: uma proposta de gestão da criatividade para o desenvolvimento da inovação. 2006. 193 f. Dissertação (mestrado) - Universidade Federal do Rio de Janeiro, Curso de Pós-Graduação em Engenharia de Produção.

KNELLER, George F. Arte e ciência da criatividade. [ tradução J. Reis]. 14 ed. São Paulo: Ibrasa, 1978.

LÖBACH, Bernd. Design industrial: bases para a configuração dos produtos industriais. São Paulo: Edgard Blücher, 2001.

LUBART, Todd. Psicologia da criatividade. Porto Alegre: Artmed, 2007.

OLIVEIRA, Débora Pereira; SILVA, Dener Luiz da; CAVALCANTE, Rita Laura Avelino. Barreiras à criatividade e reflexões sobre o papel do professor. In: CONGRESSO NACIONAL DE PSICOLOGIA ESCOLAR E EDUCACIONAL, 10, 2011, Maringá. Anais... X CONPE, Maringá: UEM, 2011. p. 1-14

OLIVEIRA, Zélia Maria Freire de. Fatores influentes no desenvolvimento do potencial criativo. Estudos de Psicologia. Campinas. v 27(1), p 83-92, janeiro - março, 2010.

OSTROWER, Fayga. Criatividade e processos de criação. 24 ed. Petrópolis: Editora Vozes, 2009.

PEARSON EDUCATION DO BRASIL. Criatividade e inovação. Academia Pearson. São Paulo: Pearson Prentice Hall, 2011.

SEABRA, Joana Miguel. Criatividade. Psicologia.com.pt: 0 portal dos psicólogos. 11 Jul. 2008. Disponível na internet por http em:

< http://www.psicologia.pt/artigos/textos/TL0104.pdf.> Acesso em 29 fev. 2012.

WIDMAIER, E. P.; RAFF, H.; STRANG, K. T.. Fisiologia humana: os mecanismos das funções corporais. 9. ed.. Rio de Janeiro: Guanabara Koogan, 2006. 